\title{
3D MODELLING BETWEEN IDEATION, GEOMETRY, AND SURVEYED ARCHITECTURE: THE CASE OF THE VAULTED SYSTEM OF ‘APPARTAMENTO DI MEZZANOTTE' IN PALAZZO CARIGNANO
}

\author{
R. Spallone ${ }^{1}$, M. Vitali ${ }^{1 *}$, F. Natta ${ }^{2}$ \\ ${ }^{1}$ Dept. of Architecture and Design, Politecnico di Torino, Torino, Italy - (roberta.spallone, marco.vitali)@polito.it \\ ${ }^{2}$ Architect, via San Martino 16, 14021 Buttigliera d'Asti, Italy - natta.fabrizio@gmail.com
}

Commission II, WG II/8

KEY WORDS: 3D modelling, survey, geometry, vaulted systems, Guarino Guarini

\begin{abstract}
:
The present work focuses on the study of vaulted systems by Guarini, by virtue of the paradigmatic role that Guarini assumes in the field of studies dedicated to this topic. The research has been compared in-depth analysis aimed at connecting relevant data with archival drawings, historical studies and treatises in order to use digital representation in heuristic terms. The attempt is to delineate and explain, through the analysis of architectural artifacts, the links between theorizations, transformations of reference geometric models and buildings. The 'Appartamento di Mezzanotte' (northern apartment) of Palazzo Carignano was choosen as a case study, because the different vaulted rooms that compose it witness the creative inspiration by Guarini and allow to structure a study that produce interesting results in relation to the connections between theoretical studies, research and cultural heritage. The use of digital representation integrated with photo-modelling $(S f M)$ tries to create new tools to investigate these different fields in their absolute and relationship value.
\end{abstract}

\section{INTRODUCTION}

The present work focuses on the study of vaulted systems created by Guarino Guarini. Guarini (1624-1683), was a priest of the Theatines order and a theorist interested in different fields of knowledge, mainly architecture, mathematics and philosophy. He lived in a century during which a leading position of geometry within the philosophical method established, thanks to the works of scientists as Galileo, Bacon, Descartes, Malebranche, Desargues. The link between geometry and architecture was one of the most important ambits of Guarini's scientific research that had significant results in the architectural practice. Inserting himself into the Baroque tradition and drawing on the theoretical assumptions of stylistically and temporally different architectural cultures, Guarini renewed the constructive language, bringing art and science into a single system. Before settling in Turin in 1666, Guarini travelled in Italy and France, where he applied to theoretical studies and architectural design. During his stay in Turin, he published some of his most important treatises and created a series of religious and civil architectures, emblematic of the Baroque period, characterized by new geometrically shaped vaulted systems. Among them, Palazzo Carignano, that is the subject of the present paper, whose first design drawings date back to 1678-1679.

The geometric study, the survey and 3D modelling of the vaults of the 'Appartamento di Mezzanotte' in Palazzo Carignano has been compared with the in-depth analysis aimed at connecting relevant data with Guarini's treatises and archival drawings in order to use digital representation in heuristic terms. The attempt is to delineate and explain, through the analysis of architectural artifacts, the links between theorizations, transformations and changes of reference geometric models, and achievements in their absolute value and of relationship through the use of digital modelling integrated with photo-modelling (SfM).

In this sense every single disciplinary theme dealt with finds significance if related to the creative process and to the implementation of the architectural construction:
- survey (in its qualitative and quantitative components) as a system of interpretation and knowledge, from design ideas to the current state;

- geometry as an expressive form of generation of the design's shapes;

- representation as an instrument for the control and verification of formal hypotheses;

- digital re-construction for the deepening of site knowledge and practices;

- visualization and rendering for the understanding and communication of the relationships between the shapes geometry, the structural nature of the construction and the decorative apparatus.

The case study presented in this paper inserts itself in a research line carried out by two of the authors since 2012 (Spallone, Vitali, 2017), regarding the masonry vaults in Baroque civil architecture of Piedmont. They were involved as supervisors with Edoardo Piccoli, an architectural historian, in the Master Thesis which results are at the basis of the case study developed in the present proposal.

\section{GEOMETRY OF GUARINI'S VAULTED SYSTEM BETWEEN TREATISES AND ARCHIVAL ORIGINAL DRAWINGS}

Guarini developed a systematic reasoning on vaulted systems into three treatises: Architettura Civile (posthumous, 1737), Euclides adauctus (1671), and Modo di misurare le fabriche (1674), in which he treated with text and images the geometric origin, the stereotomy, and the measurement of the vaults, respectively.

Among them, the Euclides adauctus represents the theoretical reference based on pure geometry, in comparison with the focus of the other two books that refers to the architectural practice.

\footnotetext{
* Corresponding author
} 

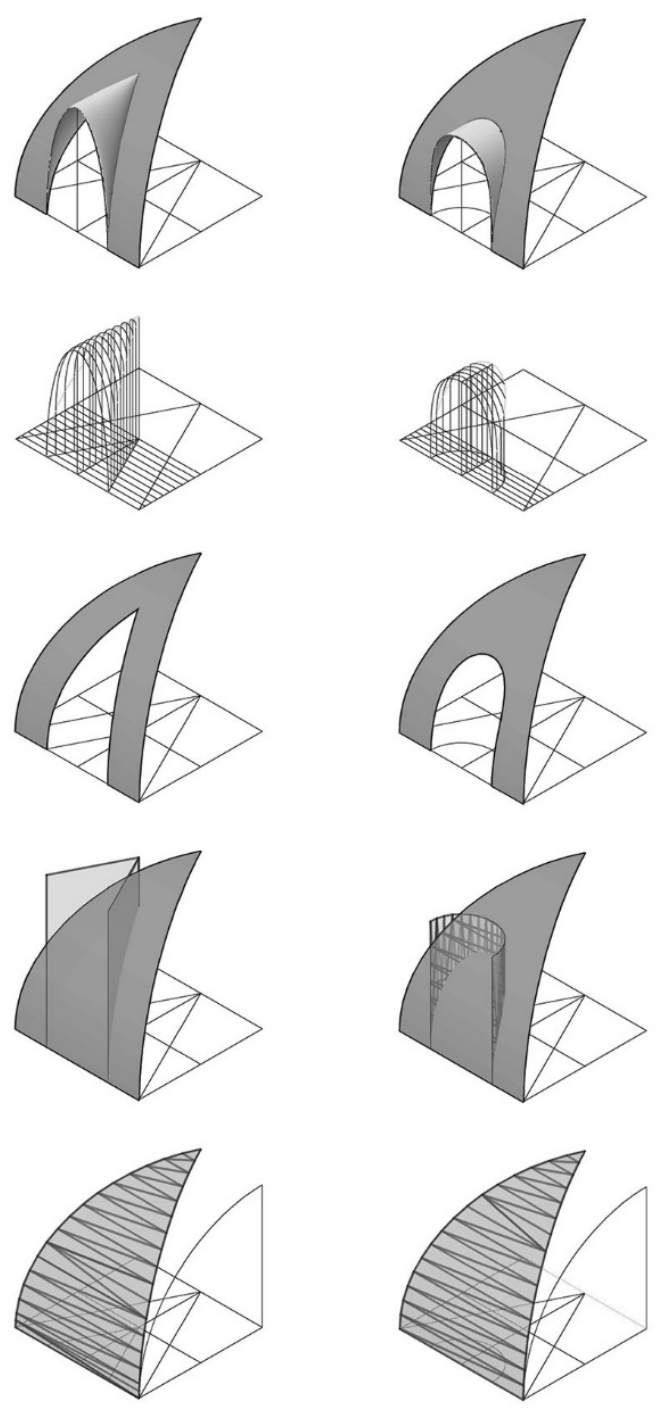

B
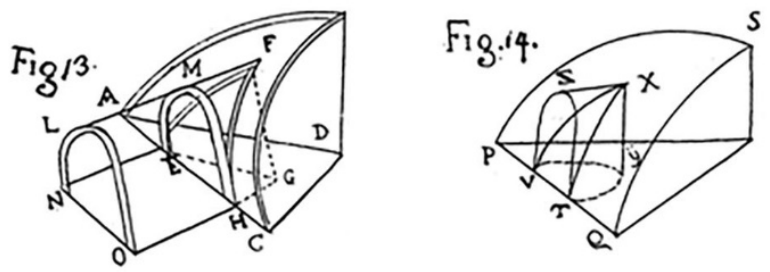

Figure 1. Lunette vaults in Plate XIX of Architettura Civile (Modelling: R. Spallone)

In this paragraph will be outlined the most important references for the development of the geometric analysis of the vaults in the 'Appartamento di Mezzanotte' found in the theoretical activity and design practice by Guarini.

In the Architettura Civile Guarini established a real vocabulary of shapes geometrically based (Spallone, 2016), starting from 'six round bodies': the surfaces of cylinder, cone, conoid, sphere, rotational ellipsoid/ovaloid, and scalene ellipsoid/ovaloid. The combination of these primitive surfaces by cuts and compositions gives rise to the well-known barrels, conical, conoidal, groins, cloisters vaults, and to domes, sails, and pendentives. Finally, there are the lunette vaults, that are composed by lunettes inserted in the surfaces previously described. For this reason, a lunette vault could be composed by a main vault (barrel, cross, cloister, dome, sail) that is cut and completed by groins.
Regarding to the lunette vaults, Guarini specified that in all the aforementioned vaults can be made cuts that does not arrive in the middle of them, starting from triangular, circular, or square plans. Then, the void is filled with a piece of 'cylinder' cut starting from the same triangular, circular, or square plans (Guarini, 1737). Guarini improperly defines the surface of the lunette as a portion of cylinder cut by the same planes that intersect the vault. But, for creating the joint between the two surfaces, this lunette cannot be geometrically defined as cylindrical: indeed, it must be generated by parallel and variable sections (like arcs of circumference or ellipse) (Figure 1).

Nevertheless, this excerpt is very important for understanding Guarini's design method, because it shows clearly that he defined the shape of the vaulted system starting from its orthographic projection in plan and that he started to define a main vault that was subsequently cut and filled.

Moreover, the lunette vaults emerged as a typology rich of shape variations and implementations in Baroque palaces, because they increase the natural lighting of the rooms and ensure airiness and dynamism to the spaces. Guarini himself, going beyond the models of late Renaissance lunette vaults on rectangular plan, created a lot of different shapes of lunettes (also present in the 'Appartamento di Mezzanotte') and invented a new radiocentric system on oval plan, that he applied to the designs of the atria in Palazzo Carignano and Palazzo Provana di Collegno.

At the end of Architettura Civile were published other plates from Guarini's Dissegni d'architettura civile et ecclesiastica (1686). Among them the unbuilt design of the Castello di Govone shows a lunette vault that can be related to the Renaissance models (Figure 2).

Another kind of vault is the 'a fasce' vault, the invention of which Guarini attributes to himself. In this case, the space to be covered by a unique vault is divided by arches, linear lintels, or architraves and in the resulting fields are built single vaults that, as Guarini states, leave great spaces for painting. In the figures 4 and 5 of plate XX there are two 'a fasce' vaults, defined by arches and linear lintels, respectively (Figure 3).

They are characterized by Guarini's choice to dispose diagonally the 'fasce', and this configuration transmits a rotational movement to the vault, similar to that of the domes in Guarini's churches.

Conversely, the schemes that present the 'fasce' in parallel with the perimeter walls are diffused in the late Baroque architectures, when architects like Juvarra and Plantery wanted to create very large rooms covered by a vault without intermediate piers.

Also the 'a fasce' vaults are present in the 'Appartamento di Mezzanotte'.

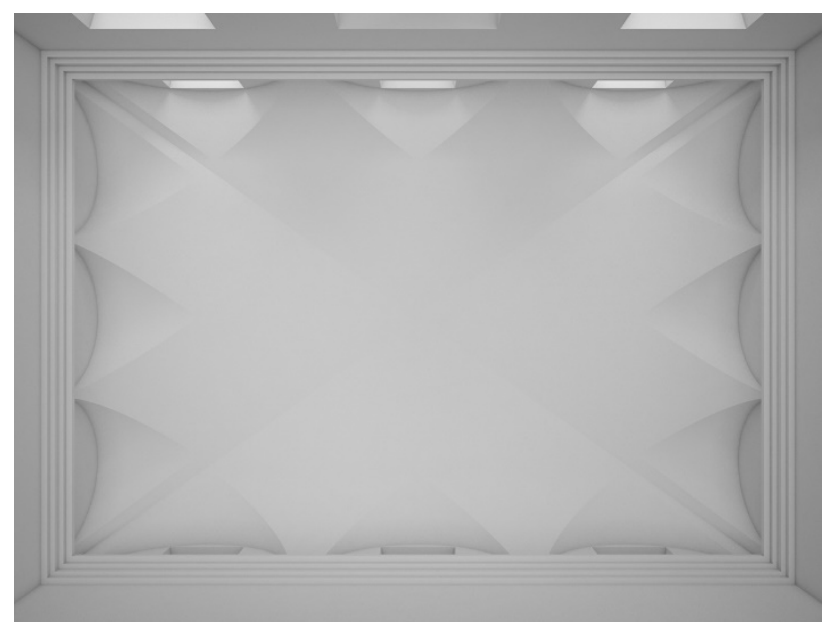

Figure 2. Reconstructive digital model of the lunette vault in the Castello di Govone (Modelling: F. Natta) 


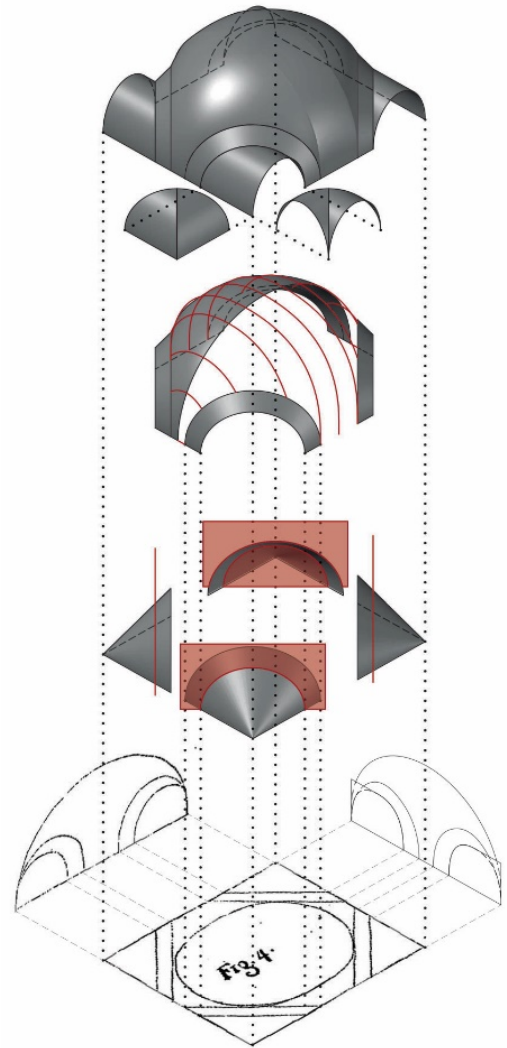

Figure 3. 'A fasce' vault in Plate XX of the Architettura Civile (Modelling: F. Natta)

In the Modo di misurare le fabriche Guarini expressed the desire to make the geometric principles developed in the Euclides adauctus applicable and accessible. In the treatise, the elements that make up the vaulted systems (coves, groins, and domes) are reduced to the simple geometries that shape them. Nineteen propositions refer to the calculation of the intrados surface of the vaults; further evidence of the importance that the author attributed to the vaults theme (Spallone, 2019).

The description follows the same order of the six round bodies seen above, according to geometric primitives, here reduced to four (since conoid and scalene ellipsoid are absent): cylinder, cone, sphere, and rotational ellipsoid and widening to their sections.

The geometric constructions and surface measurements of more than thirty shape variations applicable to the vaults are proposed; twenty of them add new opportunities to the casuistry exposed in the
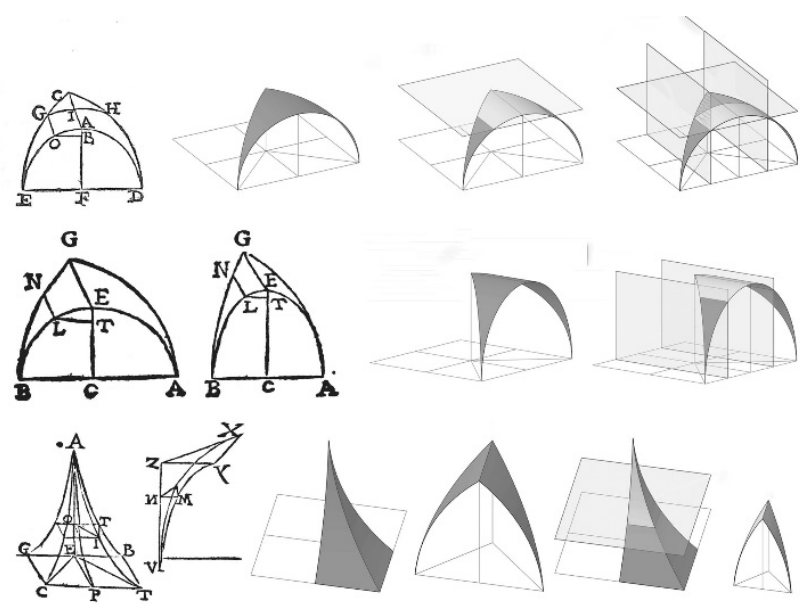

Figure 4. Lunettes in the Modo di misurare le fabriche (Modelling: R. Spallone)
Architettura civile. Among these, the lunettes, considered both as parts of cross vaults and as completion elements of main vaults, present several formal novelties. This is due to the reference to different directices: semi-ellipse, arc of circumference, arc of ellipse, and pointed arc, that Guarini added to the semi- circumference used in the Architettura civile (Figure 4).

The new shapes proposed in the Modo di misurare le fabriche are particularly suitable to the real requirements of Baroque architecture. Indeed, the book was written with the aim to help the Savoy's Superintendent of Finance in the checking of building works during the second expansion of the baroque Turin, so the geometric vaults' elements of which Guarini explained the surface calculation method are clearly inspired by those built in the city center in that period. For example, the semi-elliptical lunettes are frequent in the vaults of large rooms between $17^{\text {th }}$ and $18^{\text {th }}$ centuries, allowing the creation of radiocentric or axial systems permeable to light even in presence of reduced rises, and the lunettes having as a directrix round or elliptic arcs are widely used in the service rooms of reduced height, and the calotte domes are diffusely used as the central crowning of the halls, as can be seen in a room of the 'Appartamento di Mezzanotte'.

Other sources at the base of the geometrical analysis of the vaults in the 'Appartamento di Mezzanotte' have been analyzed and, as in the case of the treatises, several 3D reconstructive digital models have been created starting from them.

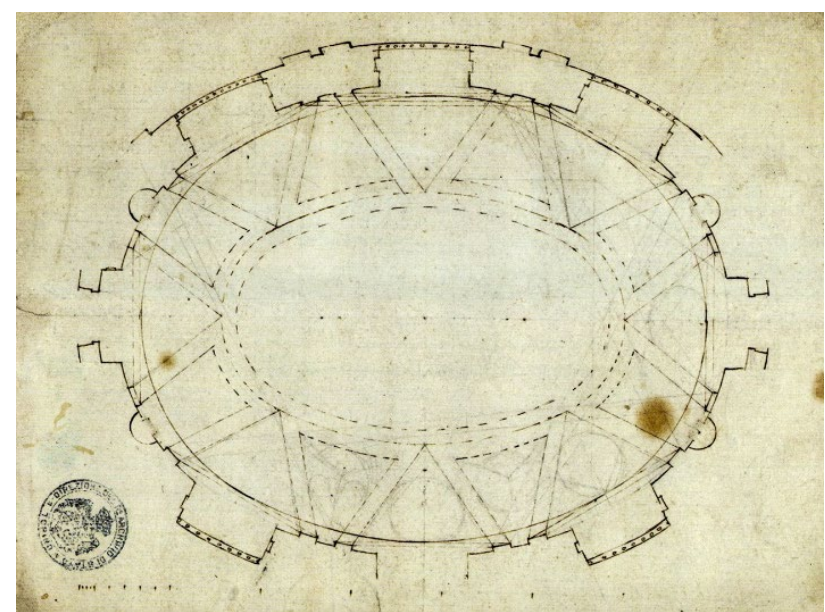

Figure 5. Study for the voult of the main hall of Palazzo Carignano, 1682 c. Torino, Archivio di Stato, Azienda Savoia Carignano, cat. 53, mazzo 1, fasc. 9, n. 29 (Lange XXXX: 64)

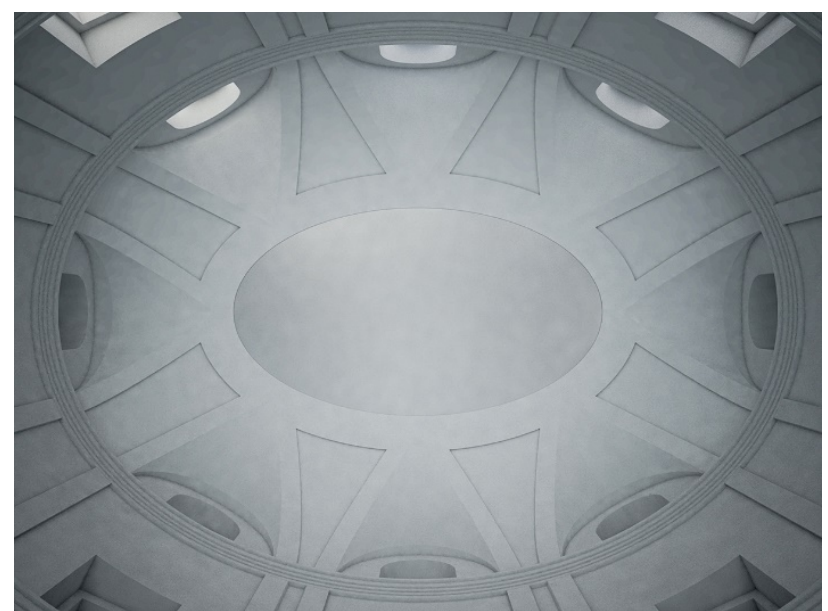

Figure 6. Digital reconstrucrtion of the vault of the main hall of Palazzo Carignano (Modelling: F. Natta) 
They are the original drawings discovered and classified by Augusta Lange at the end of the Sixties (Lange, 1970), and preserved by the Archivio di Stato di Torino. Among them, there is a design drawing for the vault placed on the oval plan of the main hall at the noble level, that is superimposed to the atrium (Figure 5).

This vault today is not the original, that, as Huub Van Der Linden (2013) wrote, was quite clearly described by Ercole Agostino Berò between 1684 e 1685 in the program for the decoration of Palazzo Carignano. Berò explained that the vault was an oval lunette dome with a central large oval oculus. Between the eight lunettes there were eight windows, among them only three are opened. The lunettes and the oculus were outlined by arches in relief, conceptually not different from the 'fasce', also for their structural function. Around and above this vault there was a tambour surmounted by another vault. The great theatrical effect of the original state, in which the second vault superimposed to the tambour was visible through the large ovate oculus in the lower dome, was lost when, in the early eighteenth century, one of the chains of the complex system that held the second vault broke and it was decided to dismantle it, and to close the opening of the first with a cover of wood and glass (Van Der Linden, 2013).

Berò's description is consistent with Guarini's original drawing, so, integrating the two sources it was possible to digitally reconstruct the probable shape of this complex vault that appears like a mix of lunette and 'a fasce' vault (Figure 6).

As said, both lunette vaults and an 'a fasce' vaults cover a great part of the rooms in the 'Appartamento di Mezzanotte', for this reason the geometrical research and the $3 \mathrm{D}$ reconstructive digital modelling on the bibliographic and archival sources, accurately selected for their similarities with the case study, could be an effective basis for the following phases of the research.

\section{SFM SURVEY}

In the following phase of the study developed in the 'Appartamento di Mezzanotte' (Midnight Apartment) of Palazzo Carignano, the principles and theories analyzed in Guarini's writings were the basis for understanding the architectural artifact created in the rooms of this apartment. Through a photogrammetric survey carried out, we then focused, also at the level of photographic sets, on the vaulted apparatus of this part of the palace. The SfM (Structure from Motion) survey technique was therefore a support and a connection for research in the theoretical field and in cultural heritage. The result obtained was a support for the subsequent studies about the geometricdescriptive characters, which are the fulcrum of this research.

The Apartment currently has ten rooms, of which only two have not been surveyed in this campaign as they did not have relevant covering structures. The other rooms, which in this study follow the original nomenclature from the Savoia inventories of 1710 , have double-height rooms towards the court, rooms at a lower height facing the street side and a long central gallery to divide and to communicate the two parts.

The survey was managed with the integration of low-cost and fast methodologies of Automated Image-Based Modeling and direct survey methods. A first phase of photographic survey was therefore accompanied by a phase of metric survey, to acquire all the significant measurements of the architectural spaces analyzed necessary for the subsequent operations of orientation and dimensioning.

The photographs were taken with a Canon EOS 1300D with an EF-S IS II 18-55 mm lens, placing the camera on a tripod adjustable up to $1.80 \mathrm{~m}$.; made in .raw format, they have subsequently been post-produced to regulate and homogenize the photographic shots in excessively underexposed environments, being able to exploit in most of the environment only natural lighting or artificial equipment of under-use for this purpose.
The results of the campaign were then inserted into the software Agisoft Photoscan ${ }^{\circledR}$ (now Metashape ${ }^{\circledR}$ ) with which the point cloud and the mesh model of the studied rooms were generated. The requirement to analyze the geometric component of the vaulted system has led to the use of additional software, more focused on cleaning point clouds and extracting metric data from the model. Through 3 DReshaper ${ }^{\circledR}$, the point clouds of each previously generated vault were imported in a single model and cleaned of all those points not necessary for the resolution of the surface. Once the cleaning operation was completed, the mesh surface was generated, with the possibility of 'covering' any holes in the model and reconstructing the surface in its entirety. From the geometric point of view, the model already provides all the information necessary for the purpose; by intersecting section planes with a manually defined position and distance, the software allows to generate the mesh model profiles and report two-dimensional data in a CAD software. These profiles were used as a basis for generating 2D and 3D drawings.

The whole survey campaign saw the integration of extended depth-of-field camera, spherical shots and parallel wide-area photographic shots to return the geometries of the rooms, the furnishings used in the rooms and the decorative apparatus of the vaulted structure.

The first room in analysis, called "Prima Anticamera" (First Anteroom), is rectangular (12.64 x $7.27 \mathrm{~m}$.), with an impost height of $5.39 \mathrm{~m}$ and height in key of $8.72 \mathrm{~m}$. The addition and alignment of photos was focused towards the vaulted system; the closure and completeness of the point cloud has in fact encountered problems with this type of photographic shots.

Among all the rooms of the apartment, this was found to be the most uniform in terms of natural brightness as well as being free of physical impediments during photographic shots, complemented by a lighting system that guarantees a good uniformity of illumination of the intrados surface. The set of images was therefore created in advantageous conditions, without excessive post-production in the processing of images to give the good exposure of the space.

For the processing of a subsequent survey documentation, direct measurements were integrated in order to manage the sizing and orientation phases. 168 photographs were created and uploaded into the software, with focal lengths variable at $20,21,23 \mathrm{~mm}$., which led to the alignment of 156 of them following mediumquality settings for all the steps made by PhotoScan ${ }^{\circledR}$ (Table 1).

\begin{tabular}{|c|l|l|}
\hline \multirow{4}{*}{ Point Cloud } & Points & 140.768 \\
\cline { 2 - 3 } & \multicolumn{2}{|c|}{ Alignment parameters } \\
\cline { 2 - 3 } & Accuracy & Medium \\
\cline { 2 - 3 } & Key point limit & 250.000 \\
\cline { 2 - 3 } $\begin{array}{c}\text { Dense Point } \\
\text { Cloud }\end{array}$ & Tie point limit & 10.000 \\
\hline \multirow{4}{*}{ Model } & Points & 8.940 .580 \\
\cline { 2 - 3 } & Quality & Medium \\
\hline & Faces & \\
\cline { 2 - 3 } & Vertices & Medium \\
\cline { 2 - 3 } & \multicolumn{2}{|c|}{ Reconstruction parameters } \\
\cline { 2 - 3 } & Quality & 2.000 .000 \\
\cline { 2 - 3 } & Face count \\
\hline
\end{tabular}

Table 1. Processing Parameters from PhotoScan Report - 'Prima Anticamera'

The choice was oriented by the tools available for this survey and by the didactic aim of the first stages of the study. The resulting point cloud has however proved to be of good quality with regard to the vaulted system, even with many gaps and noises in the other components such as walls and flooring (Figures 7-8) 


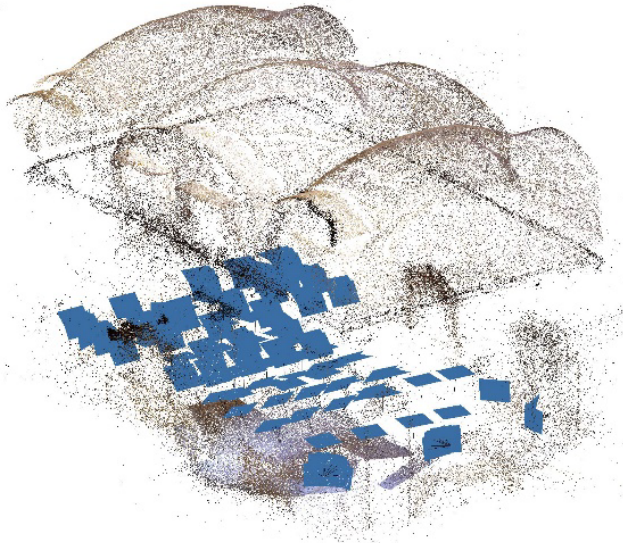

Figure 7. Sparse point cloud with aligned cameras from PhotoScan - 'Prima Anticamera' (Modelling: F. Natta)

The same processes were also performed for the study of the immediately adjacent space, the "Camera grande del letto" (Great bedroom). This other rectangular room (11.28 x $7.27 \mathrm{~m}$.) has an impost height of $5.44 \mathrm{~m}$. and a height in key of $8.24 \mathrm{~m}$ in the central part. Here, the problems of closure and completeness of the cloud have had even more emphasis that have been given by various factors:

- non-homogeneous artificial lighting system with the creation of an excessive quantity of shaded areas;

- presence of curtains along the walls resulting in the data recognition;

- dense amount of furniture throughout the floor area.

\begin{tabular}{|c|l|l|}
\hline \multirow{4}{*}{ Point Cloud } & Points & 109.588 \\
\cline { 2 - 3 } & \multicolumn{2}{|c|}{ Alignment parameters } \\
\cline { 2 - 3 } & Accuracy & Medium \\
\cline { 2 - 3 } & Key point limit & 250.000 \\
\cline { 2 - 3 } & Tie point limit & 10.000 \\
\hline \multirow{4}{*}{$\begin{array}{c}\text { Dense Point } \\
\text { Cloud }\end{array}$} & Points & 9.301 .455 \\
\cline { 2 - 3 } & Quality & Medium \\
\hline \multirow{4}{*}{ Model } & Faces & 1.860 .289 \\
\cline { 2 - 3 } & Vertices & 933.028 \\
\cline { 2 - 3 } & \multicolumn{2}{|c|}{ Reconstruction parameters } \\
\cline { 2 - 3 } & Quality & Medium \\
\cline { 2 - 3 } & Face count & 1.860 .289 \\
\hline
\end{tabular}

Table 2. Processing Parameters from PhotoScan Report 'Camera grande del letto'

The photographic survey of this room was therefore composed by the initial number of 137 photographs, previously processed in post-production to correct the underexposure of many photos, with focal lengths varying between $18,20,23 \mathrm{~mm}$., to which the alignment phase brought the selection of 122 photos for the point cloud construction. The choice of average settings within PhotoScan ${ }^{\circledR}$ (Table 2) is maintained for the same reasons previously provided, considering however good quality of the outcome obtained from the software process (Figures 9-10).

The next step brought the clouds model to a point-cleaning phase carried out in 3DReshaper ${ }^{\circledR}$. The models were imported in .ply format inside the software, analyzed and cleaned of those points excessively provided with 'noise'. Subsequently, a manual cleaning was performed by selecting points that would have created errors during the successive phases. The point clouds, cleaned and selected, then went to the mesh creation that can be subsequently managed in relation to the number of triangles and

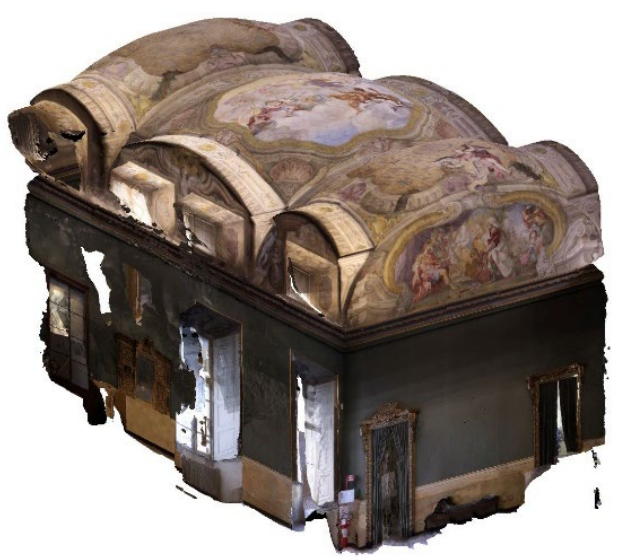

Figure 8. Textured mesh model from PhotoScan - 'Prima Anticamera' (Modelling: F. Natta)

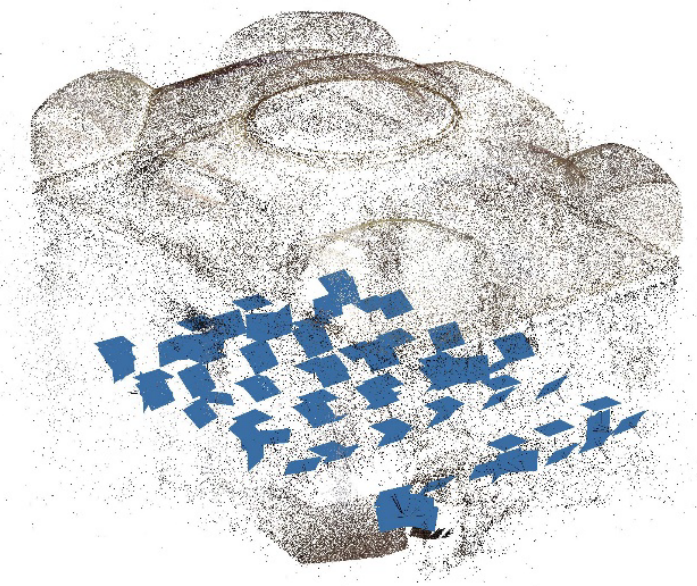

Figure 9. Sparse point cloud with aligned cameras from PhotoScan - 'Camera grande del letto' (Modelling: F. Natta)

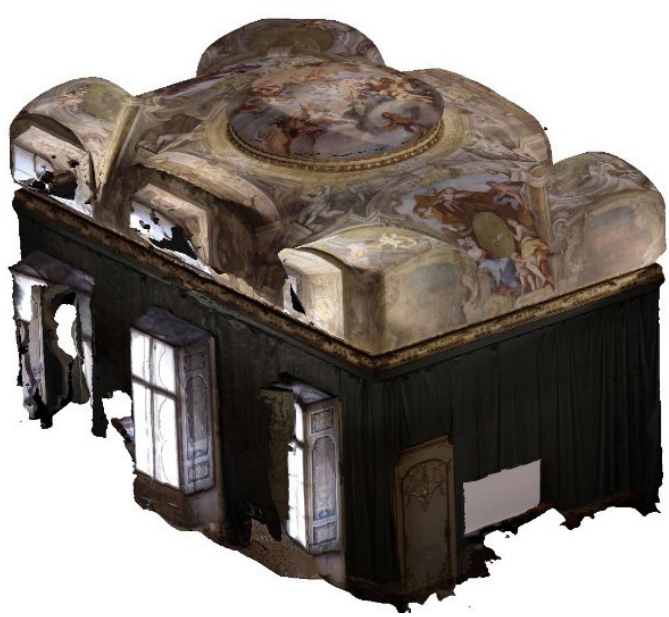

Figure 10. Textured mesh model from PhotoScan - 'Camera grande del letto' (Modelling: F. Natta)

smoothness of the models in those excessively dense areas of polygons. The software does not immediately provide good quality from RGB data, so is preferable to use in this phase the 'solid view'. It is possible to link color information to the cloud, but in order to get a more defined quality of the model, the repositioning of the texture has to be performed after a new mapping phase realized with the original photographs (Figures 11-12) 
Starting from the point cloud or from the solid mesh models it is however already possible to obtain polylines easily exportable to CAD software through the section of the object. The mesh models of the rooms have thus been dissected in the $x, y$ and $z$ axes with variable distances and an 'orthogonal grid' was generated as a base for for the subsequent geometric analysis. (Figure 13).

These data (point cloud, mesh surfaces and two-dimensional drawings) form the basis for a study on the generating geometries of the design idea related to the vaulted systems analyzed, which cannot regardless of a comparison with Guarini's treatises and original drawings, in which a considerable space is dedicated to the vaults.

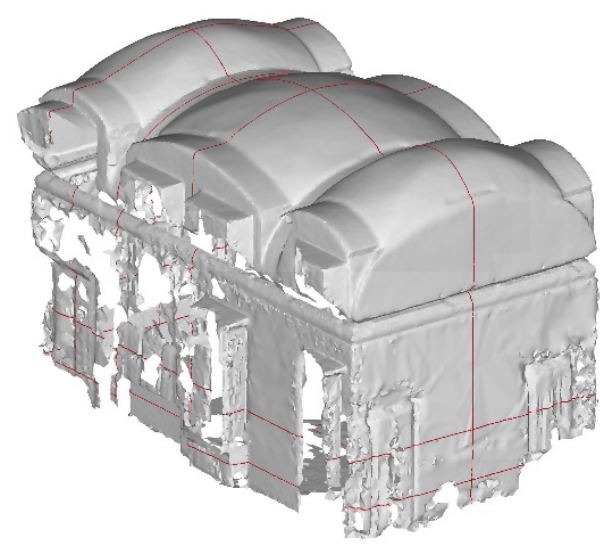

Figure 11. Solid model from 3DReshaper - 'Prima Anticamera' (Modelling: F. Natta)

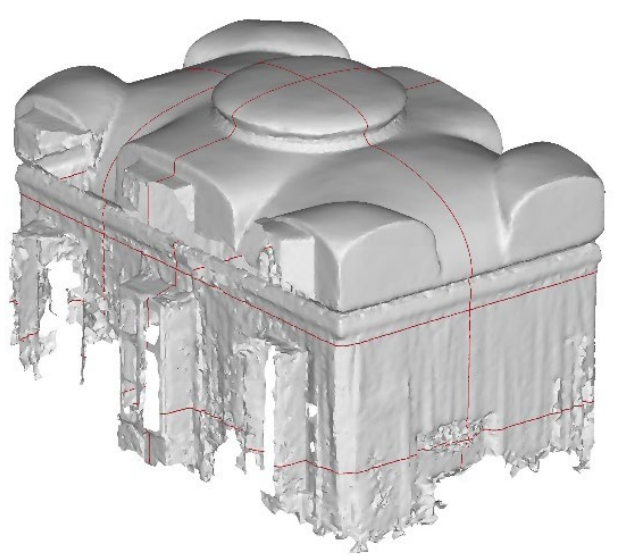

Figure 12. Figure 12. Solid model from 3DReshaper - 'Camera grande del letto' (Modelling F. Natta)

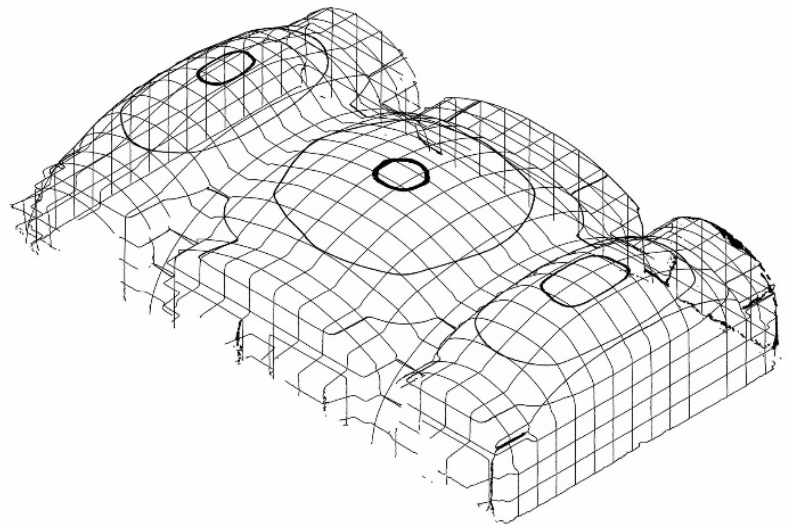

Figure 13. Polylines grid generated from 3DReshaper - 'Prima Anticamera' (Modelling: F. Natta)

\section{ANALYSIS OF SURVEY DATA AND GEOMETRIC INTERPRETATION}

The analysis phase involved the use of an approach that aims to build, based on the survey data and on the basis of the studies carried out on the sources, the theoretical models underlying the design of the vaults. The research method has already been tested in the previous phases of research on complex vaulted masonry systems: this approach is performed through the abstraction and regularization of survey data, in order to highlight the axial symmetries of the vaulted systems in relation to the combinatorial rules between the theoretical reference surfaces, independently from the irregularities of the construction

The formulation of hypotheses in relation to the geometrical design matrices starts from the study of the characteristic sections extrapolated from the 3D survey data: they are studied in order to identify similarities and correspondences with the iconographic and textual apparatus present in the sources and subsequently discretized (within a certain tolerance that takes into account the imperfections of the construction and the structural behavior of the vault) in geometrically defined shapes.

The characteristic sections, thus discretized, constitute the matrices (generatrix and directix) of the reference surfaces used for the superficial interpretative modelling. The composition of the reference surfaces, carried out through different operations produces the interpretation model that is re-evaluated in relation to the theoretical assumptions and the data of the SfM survey. The alternative geometric hypotheses formulated on the design idea can be profitably evaluated by superimposing the ideal models to the survey models, quantitatively verifying the displacements between the two surfaces.

The previous researches on complex vaulted systems have allowed us to structure a vocabulary of geometric forms and their possible combinatorial syntaxes (Vitali, Spallone, Carota, 2019) that find regular use in the schemes illustrated by Guarini in the plates of the Architettura Civile, in the design drawings analyzed in paragraph 2 , in the realized vaulted surfaces, both in the Guarinian construction sites, both in the contemporary ones, and in the subsequent realizations.

Moving on to the description of the operational phases relating to the surface modeling of the rooms that make up the case study (Figure 14), they were carried out with AutoCAD surface modelling: the continuous comparison between the survey data and the surface vocabulary systematized in Guarini's treatises allowed to formulate hypotheses of decomposition of vaulted systems in hierarchically organized surfaces.

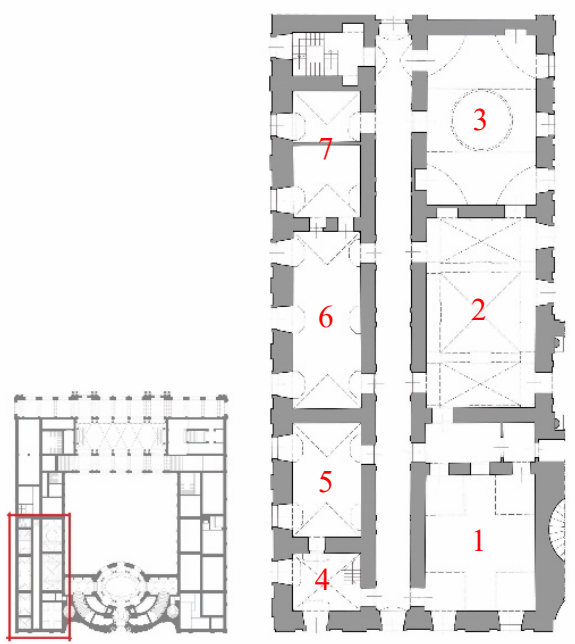

Figure 14. The 'Appartamento di Mezzanotte' in Palazzo Carignano, floor plan (Drawing: F. Natta) 


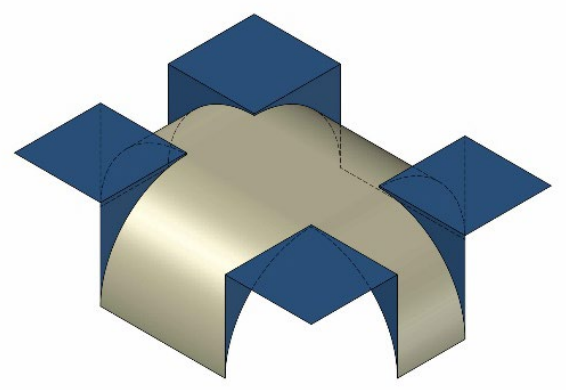

Figure 15. 3D interpretative model of the vault of room 1 (Modelling: F. Natta)

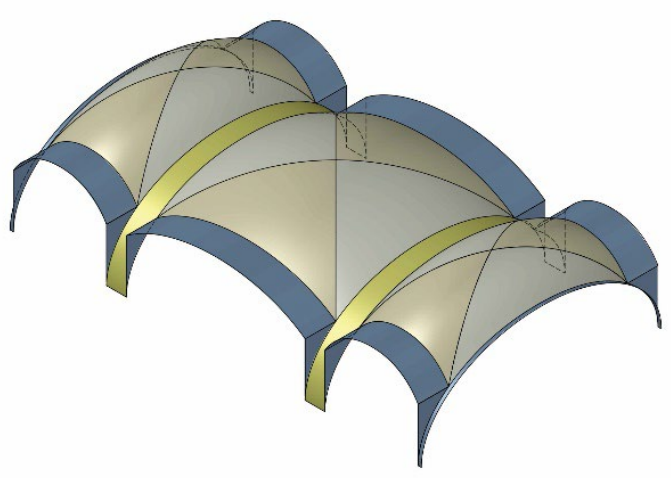

Figure 16. 3D interpretative model of the vault of 'Prima Anticamera', room 2 (Modelling: F. Natta)

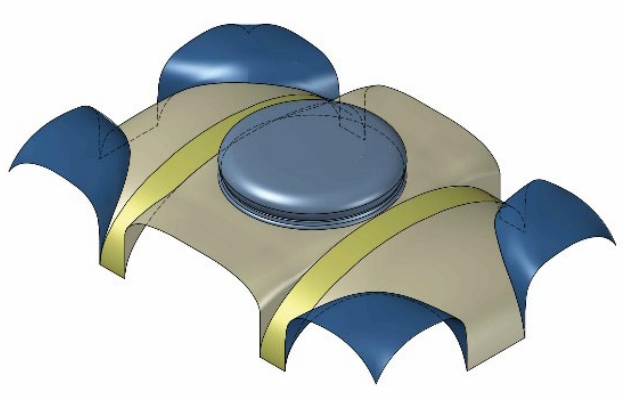

Figure 17. 3D interpretative model of the vault of 'Camera grande del letto', room 3 (Modelling: F. Natta)

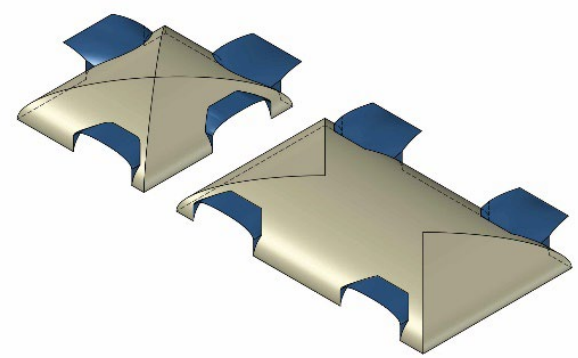

Figure 18. 3D interpretative model of the vaults of 'Gabinetto di Cantone', room 4, and of 'Salotto contiguo al Gabinetto', room 5 (Modelling: F. Natta)
In relation to the rooms' vaults, this phase of work has produced three-dimensional interpretive models that geometrically return the complexity of the architecture.

(1) the room, with rectangular proportions, is divided in plan through the construction of squares in the corners that delimit two orthogonal bands in axis to the sides of the room. These bands can be likened to portions of a cloister vault, with a flat portion in the middle. The four angular fields are covered by a flat surface (Figure $15)$.

(2) Regarding the vault of the 'Prima Anticamera', the general conformation is that of the 'a fasce' (banded) vault. Two polycentric lowered arches divide the space into three parts, the central one double than the sides. Le dimensioni del campo centrale sembrano guidare l'intera composizione: esso infatti viene ritagliato in forma quadrata lasciando spazio, lungo i lati lunghi dell'ambiente, allo sviluppo di ulteriori archi ribassati che si appoggiano con imposta gli archi principali. The three vaulted fields delimited by the arches look like sail vaults, but the analysis of the SfM model reveals surface discontinuities that allow to geometrize it through the construction of groins defined by sections (Figure 16).

(3) The vault of the 'Camera grande del letto', shows a more articulated and complex composition of surfaces than the previous example. Also this room is divided by lowered polycentric arches into three parts, in axis with the openings on the courtyard. The vaults that cover the sides of the room can be assimilated to semi- 'a conca' vaults - as Curioni states (Curioni, 1868), we mean a double curvature vault with three directrices, where the lateral ones are straight and the central ones are curved - cut in the corners by sail-like vaults. The vault covering the central field of the room is assimilated to a sail-like surface, generated by sections which lay continuously on the bands. This surface is cut by a surface with a vertical development which generates a circle tangent to the bands, almost flat, regularized by plaster frames, on which it develops a rotational ellipsoidal basin (Figure 17).

(4-7) As for the rooms that face the street, the vaulted surfaces, which all have a strongly lowered height, are built as cloister or barrel vaults with cloister heads depending on the length of the rooms. The generatrix sections of the surfaces consist of polycentric arcs. The lunettes are very interesting from a geometrical point of view: in all rooms (ignoring small differences) they have a shape defined by the polygonal projection on the ground (Figure 18).

The axonometric views have been tructured to show the hierarchical relationships between the surfaces and to highlight the possible compositional mechanisms of main and secondary surfaces.

\section{CONCLUSION}

Since the design theoretical scheme are very often hidden in architecture because of the techniques of bricks, the superimposition of plaster and the decorative apparatus, we think that representation tools can be profitably used, on one hand as a tool of study in order to allow research advances on vaulted systems, on the other to support the dissemination and the enhancement of cultural heritage in a didactic way.

The last image (Figure 19) is composed with this particular didactic aim: the ideal model realized on CAD is rendered with the 3Dstudio Max software and compared to the clean and closed SfM model. Through the overlap of the two models we tried to highlight in a single image the geometry of the space, the shapes of the built architecture, the shapes evoked by the pictorial decoration. The goal of this representation is to highlight the meaning relations between the models, which connect the geometry with the mechanisms of the architectural construction 
and with the interferences or assonances generated by a wise use of decoration.

The continuous progress in the digital world always opens up new possibilities in the field of representation, as well as survey: in particular, in regard to fruition and sharing, AI, AR and VR technologies are increasingly required to be more heritage oriented. Techniques advance and Cultural Heritage can use new tools for analysis, interpretation, communication, use and sharing.

The wide documentary patrimony, among archival materials, architectural literature, designed architectures, manufactured artifacts, until now analyzed for a specific case, can become the basis of explorations that draw from the tools offered by the digital revolution new and original ideas and themes of research to be investigated in a multidisciplinary perspective aimed at enhancing the knowledge of architectural heritage.

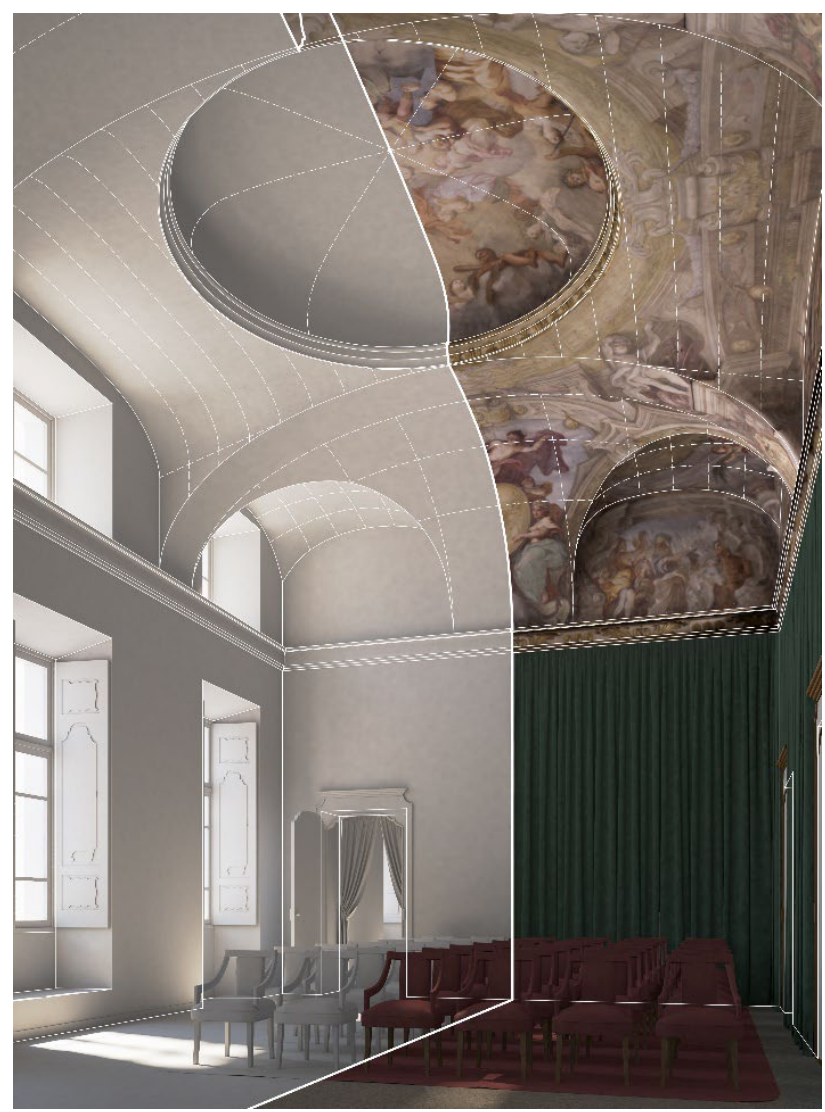

Figure 19. Superimposition of SfM 3d model and interpretative geometric model of 'Camera grande del letto'

(Modelling: F. Natta)

This paper is a development of the research project on Complex Vaults systems carried out by Roberta Spallone and Marco Vitali since 2012. The case study, previously analysed by Fabrizio Natta within his MSc thesis (supervisor: Roberta Spallone, advisor: Marco Vitali), has been enhanced for the aims of the present research. Roberta Spallone wrote paragraphs 2, Fabrizio Natta wrote paragraph 3, Marco Vitali wrote paragraph 4. Paragraph 1 and 5 were written together by Roberta Spallone, Marco Vitali and Fabrizio Natta.

\section{REFERENCES}

Apollonio, F.I., 2012. Architettura in 3D. Modelli digitali per $i$ sistemi cognitivi. Bruno Mondadori, Milano.
Curioni, G., 1865. Geometria pratica applicata all'arte del costruttore. Negro, Torino.

Dardanello, G., Klaiber, S., Millon, H. A. (eds.), 2006. Guarino Guarini. Allemandi, Torino.

De Luca, L., 2011. La fotomodellazione architettonica. Rilievo, modellazione, rappresentazione di edifici a partire da fotografie. Dario Flaccovio, Palermo.

Guarini, G., 1671. Euclides adauctus et methodicus, matematicaque universalis. Typis Bartolomeai Zapatae, Torino.

Guarini, G., 1674. Modo di misurare le fabriche. Per gl'heredi Gianelli, Torino.

Guarini, G., 1686. Dissegni d'architettura civile et ecclesiastica, inventati et delineati dal Padre D. Guarino Guarini. Domenico Paulino, Torino.

Guarini, G., 1737. Architettura Civile. Appresso G. Mairesse, Torino.

Guidi, G., 2014. La digitalizzazione dei Beni Culturali. In: Irace, F. (ed.). Design \& Cultural Heritage. Immateriale Virtuale Interattivo. Electa, Milano, pp. 55-82.

Lange, A., 1970. Disegni e documenti di Guarino Guarini: catalogo dei disegni manoscritti. In: Guarino Guarini e l'internazionalità del Barocco, vol. 1. Accademia delle Scienze, Torino, pp. 91-283.

Piccoli, E., 2006. Disegni di Guarini per le volte di edifici civili. In: Dardanello, G., Klaiber, S., Millon H. A. (eds.). Guarino Guarini. Allemandi, Torino, pp. 43-49.

Spallone, R., 2016. "Delle volte, e vari modi di farle". Modelli digitali interpretativi delle lastre XIX e XX nell'Architettura Civile di Guarini, fra progetti e realizzazioni / "On the vaults and various modes of making them". Interpretative digital models of the XIX and XX plates in Guarini's Architettura Civile, between designs and buildings. In: Bertocci, S., Bini, M. (eds.). Le Ragioni del Disegno. Pensiero Forma e Modello nella Gestione della Complessità / The Reasons of Drawing. Thought Shape and Model in the Complexity Management. Gangemi, Roma, pp. 1275-1282.

Spallone, R., 2019. Geometry, Arithmetic, Architecture. Calculation Methods for Vault Surfaces in the Modo di Misurare le Fabriche by Guarini. In: Cocchiarella, L. (ed.). ICGG 2018 Proceedings of the 18th International Conference on Geometry and Graphics. ICGG 2018. Advances in Intelligent Systems and Computing, vol 809. Springer, Cham, pp. 2108-2119. https://doi.org/10.1007/978-3-319-95588-9_188

Spallone, R., Vitali, M., 2017. Volte stellari e Planteriane negli atri barocchi in Torino. Star-shaped and Planterian Vaults in the Baroque Atria of Turin. Aracne, Ariccia.

Van Der Linden, H., 2013. Un secentesco programma di decorazione per il grande salone di Palazzo Carignano. Rivista d'arte, V(III), pp. 257-297.

Vitali, M., Spallone, R, Carota, F., 2019. Parametric Modeling as a Tool of Analysis and Interpretation of Built Heritage: The Case Study of Complex Baroque Vaults. In: Ippolito, A., Inglese, C. (eds.). Analysis, Conservation, and Restoration of Tangible and Intangible Cultural Heritage, IGI Global, Hershey, pp. 366-401. 